\title{
Anti-MAGE-A4 T-cell Receptor/Anti-CD3 scFv Fusion Protein IMC-C103C
}

National Cancer Institute

\section{Source}

National Cancer Institute. Anti-MAGE-A4 T-cell Receptor/Anti-CD3 scFv Fusion Protein

IMC-C103C. NCI Thesaurus. Code C162462.

A T-cell re-directing bi-specific biologic composed of a modified form of human T-cell receptor (TCR) specific for the tumor-associated antigen (TAA) human melanomaassociated antigen A4 (MAGE-A4) and fused to an anti-CD3 sing le-chain variable fragment (scFv), with potential antineoplastic activity. Upon intravenous administration of IMC-C103C, the TCR moiety of this agent targ ets and binds to MAGE-A4 on tumor cells and the anti-CD3 scFv moiety binds to CD3- expressing T-lymphocytes. This selectively cross-links tumor cells and T-lymphocytes and results in a CT L-mediated death of MAGEA4-expressing tumor cells. MAGE-A4 is overexpressed by a variety of cancer cell types. 